\title{
A rare case of acute Clozapine - related thrombogenic myocarditis
}

\author{
Un raro caso di miocardite trombogenica \\ acuta da clozapina
}

\author{
Antonietta Evangelista, Matteo Ruzzolini, Carlo Peraldo Neja, Paolo Azzolini
}

Monaldi Arch Chest Dis 2014; 82: 202-203.

San Giovanni Calibita - Fatebenefratelli Hospital, Rome, Italy.

Corresponding author: Dott. Paolo Azzolini; Ospedale San Giovanni Calibita - Fatebenefratelli, Isola Tiberina, via Ponte di Quattro Capi; I-00186Roma, Italy; E-mail address: paolo.azzolini@tin.it

A man aged 30 years with history of treatment resistant chronic schizophrenia and no cardiovascular $(\mathrm{CV})$ risk factors was admitted to our psychiatric unit to discontinue his current antipsychotic medications and to start clozapine. Some other antipsychotic medications (Promazine, Aloperidol, Delorazepam, Valproic sodium) were coadministered with clozapine for some days before being discontinued. Incremental doses of clozapine was started (from $50 \mathrm{mg}$ /day to $100 \mathrm{mg} /$ day). Except for mild sedation, no adverse events were noted during his first 13 - days admission until when he presented new symptoms such as fever $\left(38.5^{\circ} \mathrm{C}\right.$ temp), gastrointestinal symptoms such as diarrhea and subjective sensation of chest discomfort. Two days later symptoms worsened with onset of hypotension (BP $90 / 50 \mathrm{mmHg}$ ), dyspnea and tachycardia. Electrocardiogram showed sinus tachycardia (140 bpm), anterior ST elevation, ventricular premature beats. Chest radiograph was normal. Transtoracic echocardiograpy showed reduced Ejection Fraction (37\%), apical and inferior wall hypokinesis, big mobile apical thrombus, mild right ventricle hypokinesis (TAPSE $18 \mathrm{~mm}$ ) and mild anterior and lateral pericardial effusion, ecofree space $6 \mathrm{~mm}$ (Fig. 1). Laboratory data showed normal peripheral blood cell count, increased serum concentrations of high -sensitivity troponin $(0,539 \mathrm{ng} / \mathrm{ml})$, creatinine kinase (336 U/L), creatinine kinase-MB (10.5 ng/ml), Btype natriuretic peptide $(11828 \mathrm{pg} / \mathrm{ml})$, C-reactive protein $(38,7 \mathrm{mg} / \mathrm{dl})$ and D-dimer $(1082 \mathrm{ng} / \mathrm{ml})$ levels. Because of the patient's young age, absence of CV risk factors, fever and diarrhea we suspected an acute myocarditis since the beginning and did'nt perform coronary angiography.

We administrated heart failure therapy (diuretics, beta blockers, ACE-Inibitors), low molecular weight heparin, antiviral, antimicotical and antibiotic drugs. One week later a very strong hypereosinophilia appeared in the blood cell count, transthoracic echocardiograpy showed recovered
LV contractility, improved Ejection Fraction (60\%), disappearance of apical thrombus. Heart failure symptoms improved except onset of diarrhoea and vomiting and increased serum concentration of amylase and lipase levels, because of these findings an abdominal CT was performed showing spleen infarction (Fig. 2) compatible with ischaemic lesion secondary to cardiac embolization. Once Clozapine - Related Myocarditis (CRM) has been diagnosed, Clozapine was immediately stopped improving cardiac function and clinical outcame. Our patient was discharged in good health except for his psychiatric disease still under treatment with other antipsychotic drugs. Pathophysiology of CRM is still not clear in literature but the most widely accepted is as a consequence of a drug hypersensitivity reaction with peripheral eosinophilia caused by an Immunoglobulin E mediated hypersensitivity.

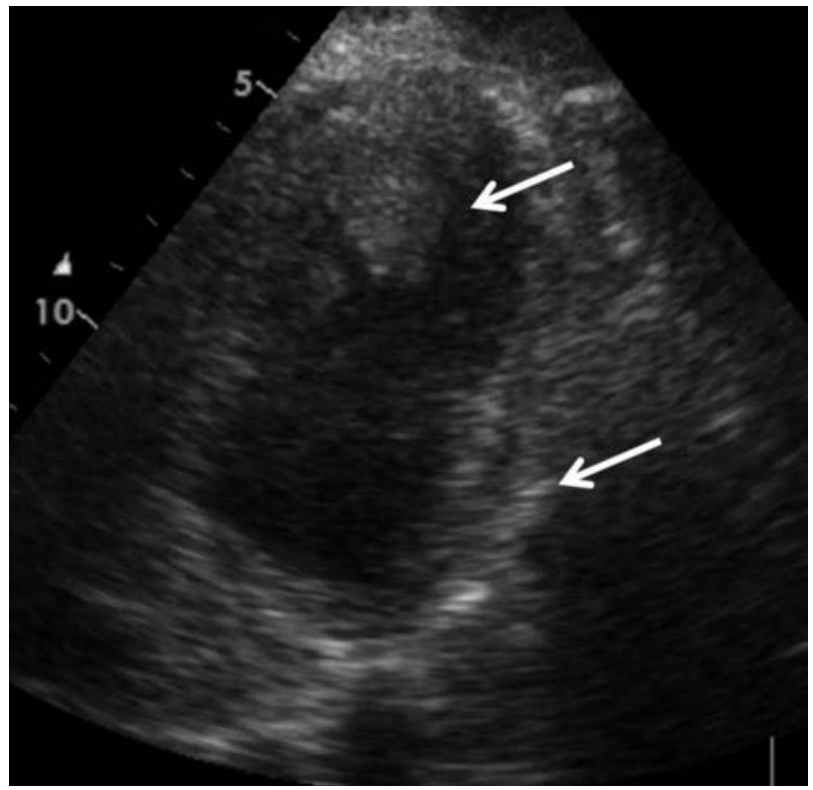

Figure 1 


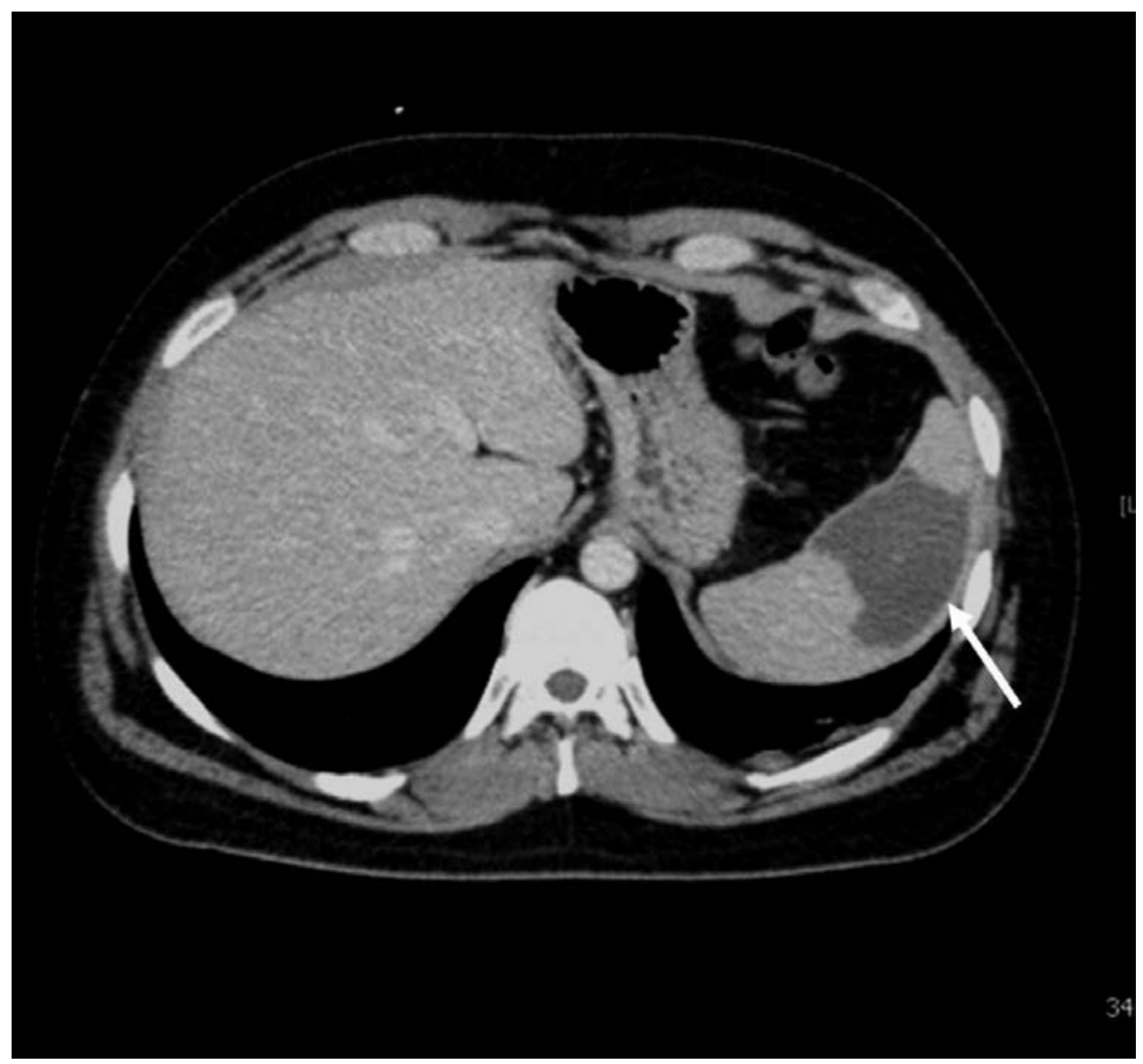

Figure 2

After CMR diagnosis It is mandatory to immediately stop clozapine treatment, the early cessation may improve the clinical outcome and LV dysfunction.

Most patients with acute CMR respond well to standard heart failure therapy. When you start Clozapine titolation you must schedule a monitoring program to early recognize toxic drug effect including cardiac enzymes, C-reactive protein and echocardiography.

\section{References}

1. JC Kilian, K. Kerr et al. Myocarditis and cardiomyopathy associated with clozapine. The Lancet 1999; 354: 1841-45.

2. D. De Bernardis, N. Serroni et al. Update on the adverse effects of clozapine: focus on myocarditis. Current Drug Safety, 2012; 7: 55-62.

3. P. Manu, D. Sarpal et al. When can patients with potentially life-threatening adverse effects be rechallenged with clozapine? Systematic review of the published literature. Schizophr Res 2012134 (2-3): 180-186. 